for young psychiatrists and those wanting some initial land marks and stimulation but they are inevitably highly individual statements.

\section{Crosscurrents in Psychiatry and Psychoanalysis}

Edited by Robert W. Gibson. Pp. 259. Philadelphia and Toronto: J. B. Lippincott. London: Pitman Medical. 1968. 80s.

This book consists of a dozen chapters made up of invited papers each with comments from the leading discussant. The occasion, in 1966, was the 75th anniversary of the establishment of a private psychiatric hospital in Maryland, U.S.A. The main contributors are present and past members of the staff and the papers are a mixture of comments about the role and difficulties of existence of such hospitals in the present day, more psychoanalytic theorizing, and one or two snippets of research, mostly preliminary reports. This is definitely not a memorable book for those outside the institution itself-one suspects that its chief aim was to provide bait for further potential local sources of endowment fundș.

\section{Recent Advances in Respiratory Tuberculosis}

Edited by Frederick Heaf and N. Lloyd Rusby. Sixth Edition. Pp. viii +234 , illustrated. London: J. \& A. Churchill. 1968. 55s.

It is $\mathbf{8}$ years since the last edition of this book was published. It has now been completely re-written by the editors and eight other contributors. It gives an excellent account of modern chemotherapy and the problems of drug resistance with extensive lists of references. There are good chapters on 'Tuberculin Testing', 'BCG Vaccination' and the 'Opportunist Mycobacteria'. The chapter on 'Respiratory Function' is disappointing; too much of it is about esoteric techniques and tests without real application to the clinical problems of pulmonary tuberculosis.

The book attempts to deal not only with recent progress in the more technically advanced countries, but also with the problems of the developing countries of the Commonwealth. Dr Wallace Fox contributes a brilliant chapter on 'The Chemotherapy of Tuberculosis in Developing Countries'. Otherwise, the brief accounts of organization and methods in use for control of tuberculosis in different parts of the world are too superficial to be of much practical value.

The book is well written and highly readable. It should be read by everyone in Britain responsible for the prevention, diagnosis and treatment of tuberculosis. If it is, it will lead to a considerable improvement in the standard of management of tuberculosis in the country and make a major contribution to the eradication of the disease.

\section{Studies of the Development and Decay of the Human Frame} By Joseph Trueta. Pp. xiv +369 , illustrated. London: William Heinemann. 1968. £6 3s.

In this remarkable and exciting book Professor Trueta has brought together his research and considered opinions on a great variety of bone and joint disorders. Most readers are well aware that his contributions to orthopaedic literature have been numerous, but many will be surprised to find how wide-ranging and extraordinarily prolific his work has been. Nevertheless, one constant theme predominates-the blood supply; and this is epitomised by an apt quotation from Leviticus on the fly leaf 'For the Life of all Flesh is the Blood thereof'.

The book is divided into four parts.

1. From Gel to Bone.

2. From Conception to Manhood.
3. Studies of Trauma and Disease of the Skeleton.

4. The Decline.

Under these major headings he surveys a huge field, discussing subjects as varied as the origin of osteoblasts, the mechanism of calcification, growth, the origin of the circulatory system, bone implants, fractures, dystrophies, haemophilia, osteomyelitis, pseudocoxalgia, slipped epiphysis, scoliosis, Paget's disease and degenerative arthritis. Whatever the subject its underlying vascular pathology is given prominence and his studies of the blood supply of bone, especially of the upper femur, are described in considerable detail.

The forthright style and occasional petulance may disturb a few readers; so may the frequency of self-quotation, but these are probably inevitable in a work such as this which epitomises a life-time of thought, investigation and productive effort. There is scarcely a single topic which he fails to illuminate. Every future orthopaedic research worker will have to read the appropriate section of this book: he will learn much from it and from the extensive bibliography.

The paper and printing are good, the illustrations profuse and mostly of good quality and the price very reasonable. The publishers are to be congratulated on a fine production and the author on a mammoth achievement.

Electroencephalography for Anaesthesiologists and Surgeons By M. S. Sadove, D. Becka and F. A. Gibbs. Pp. $v+95$, illustrated. London: Pitman Medical. Philadelphia: J. B. Lippincott. 1968. 90s.

Recently there has been an increasing emphasis on the recording of cerebral electrical activity in both the operating 8 theatre and intensive care unit. The electroencephalographer is required to assist in the 'diagnosis of death' and to answer the question, 'Will useful cerebral function be restored in this patient?'. A new book promising to explain the fundamentals of electroencephalography to the surgeon and the anaesthetist is, therefore, welcome.

This volume, one of whose authors include Frederick Gibbs, well known for his three-volume Atlas of Electroencephalography, is divided into twelve sections. The lengthier include 'Anaesthesia' and 'Operative and Post-operative Monitoring, Cardiac Arrest and Vascular Insufficiency', the briefer sections include the technical aspects of personnel, procedure and equipment. Curiously however descriptions of the normal waking and sleep EEGs and of artefacts, occur at the end of the book instead of in a more logical position near the beginning.

The Plates at first glance appear well produced but on closer examination their annotation is found to be inadequate, and both their sequence and the arrangement in the text are unhelpful. A more basic criticism is the static approach of the authors. For example, in a paragraph headed 'Computers and Frequency Analysers' the following occurs: 'it will probably take another thirty years to convince everyone that electroencephalographic computers, like analysers cannot take the place of an intelligent, experienced operator', and the reader is provided with a reference from the year 1947. Many of the other items in the bibliography are also out of date, for example, the only reference related to the problem of the 'diagnosis of death' was published in 1957. This critical aspect of the EEG for the anaesthetist and surgeon is not discussed in sufficient detail to be helpful. The omission of corticography from the book is unfortunate for though this is a highly specialized procedure it has considerable relevance for the surgeon.

This textbook which could be valuable fails to present the subject lucidly or to indicate the potentialities of electroencephalography for either surgeon or anaesthetist. 